\title{
On the value of partial commitment for cooperative investment in buyer-supplier relationship
}

JOSE DE SOUSA, XAVIER FAIRISE

\section{www.tepp.eu}

TEPP - Institute for Labor Studies and Public Policies TEPP - Travail, Emploi et Politiques Publiques - FR CNRS 3435 
ISSN 2110-5472 


\title{
On the value of partial commitment for cooperative investment in buyer-supplier relationship $^{1}$
}

\author{
José DE SOUSA ${ }^{2}$ \\ XAVIER FAIRISE ${ }^{3}$
}

May 7, 2013

\begin{abstract}
Does formal contracting foster cooperation in a buyer-supplier relationship? In line with the literature, we find that a renegotiable contract with relationshipspecific joint investments does not make it possible to reach the first-best. However, we show that a renegotiable contract may induce more cooperation than an informal arrangement can. This result may help to understand how cooperation emerges in Japanese procurement practices, which typically involve relationshipspecific joint investments and renegotiable contracts.
\end{abstract}

Keywords: Incomplete contracts, relationship-specific investments, cooperation.

JEL Classification : K12, L22, C7.

\footnotetext{
${ }^{1}$ We would like to thank two referees for thorough and very useful comments. We are grateful to John McLaren for helpful discussions and interest about our results. Thanks also to Stefano Comino, Pierre Fleckinger, Carl Gaigné, Laurent Linnemer, Jean-François Nivet, Patrick Schmitz, Jean-Marc Tallon, Jean-Philippe Tropéano, Luis Vasconcellos and several participants at Universities of Amsterdam (EARIE), Bilbao (JIE), Paris 1 and Rennes 1 for helpful comments and suggestions. Errors are ours.

${ }^{2}$ ADIS, University of Paris Sud and CES, University of Paris 1. Tel. +33 144078192 . Fax: +33 1440781 91. E-mail: jdesousa@univ-paris1.fr

${ }^{3}$ GAINS-TEPP, Université du Maine. Tel. +3302 438331 34. E-mail: xavier.fairise@univlemans.fr.
} 


\section{Introduction}

A growing range of production activities is now subcontracted. Firms split their production process and outsource activities, from product design to assembly. This split expands vertical inter-firm relationships and trade in customized parts. In such vertical relationships, the "hold-up problem" appears to be crucial (Klein, Crawford and Alchian, 1978). The canonical example goes as follows. A buyer commissions a supplier to produce a tailor-made input. Either the supplier or both the buyer and the supplier make ex ante non-contractible and relationshipspecific investments to transact. At the (re)negotiation stage, investors are locked into the relationship and risk not receiving ex post the overall return of their autonomous investments. Two potential economic inefficiencies result from the hold-up problem. The investors may under-invest in specific assets (Grossman and Hart, 1986) and/or waste resources to protect her investment returns.

Following the classification introduced in Che and Hausch (1999), autonomous specific investments can be either 'selfish', when they generate a direct benefit only for the investor, 'purely cooperative', when the direct benefit only goes to the partner of the investor, or 'hybrid', when it offers direct benefits to both parties. A first stream of the literature concentrates on selfish investments and shows that simple renegotiable fixed-price contracts can solve the hold-up problem (Chung, 1991; Aghion, Dewatripont and Rey, 1994; Edlin and Reichelstein, 1995, 1996 and Nöldeke and Schmidt, 1995). ${ }^{4}$ Che and Hausch (1999) concentrate on purely cooperative and hybrid investments. They show that with purely cooperative investments contracting has value only if the parties can commit not to renegotiate, while renegotiable contracts offer no advantage over a simple ex post negotiation. They also show that renegotiable contracts can be valuable when investments are hybrid. In all the literature we have referred to investments are autonomous, i.e., each party decides independently from the other and one party's investment has effect even if the other decides not to invest.

In this paper we study the value of partial commitment to solve the hold-up problem for joint investments. Joint investments require an explicit cooperation between the parties: one party investment generates benefits only if the other party also invests, so that investments are complementary. In that setting, we show that with joint investments renegotiable contracts are always potentially

\footnotetext{
${ }^{4}$ See Schmitz (2001) for an excellent review of the hold-up problem and the incomplete contract literature.
} 
valuable, but never able to restore first best incentives for both parties.

This result echoes the hybrid case of Che and Hausch where a simple contract is also potentially valuable without restoring first best incentives. However, the setting is different. They coined as purely cooperative or partly cooperative (i.e., hybrid) investments that are autonomous. ${ }^{5}$ Thus, a restriction of the Che and Hausch's investments lies in their lack of joint work. In our setting, firms cooperate in the sense that their investments are complementary.

Considering joint investments may help to understand how cooperation emerges in Japanese procurement practices. Our framework roughly fits some stylized facts about the Japanese buyer-supplier relationships. First, parties trade in customized parts, which require autonomous and joint relationship-specific investments (see among others Asanuma, 1985a,b, 1989; Aoki, 1988, Nishiguchi, 1994, Qiu and Spencer, 2002 and Spencer and Qiu, 2001). As an example of joint investments, Japanese car manufacturers cooperate with suppliers to design parts of the final product. ${ }^{6}$ They coordinate tasks, share information and meet each other. This cooperation is typically linked to joint investments, which are the source of productivity improvements over time. Second, Japanese practices tend to differ from American ones in key areas such as quality control and price determination. However, characterizing Japanese arrangements as informal and cooperative and Western arrangements as formal and antagonistic is a coarse generalization. In fact, the difference is blurred, as Western firms have adopted many Japanese practices (see e.g Cusumano and Takeishi, 1991), while Japanese firms contract with their partners (Asanuma, 1985a,b, Nishiguchi, 1989). Based on a survey of automobile manufacturers, Cusumano and Takeishi (1991) provide evidence of the contractual nature of the Japanese buyer-supplier relationships. They find that, for each new model of car, parties sign a new contract. "The most common contract (62 percent of the sample) is 4 years, corresponding to the average model life-cycle" (Cusumano and Takeishi, 1991). Given that the average

\footnotetext{
${ }^{5}$ The term "cross investments" might be a more suitable name in that case. The term "cooperative investments" was coined by Che and Hausch (1999), although their main idea (i.e., that contracts are useless with purely cooperative investments when renegotiation cannot be rule out) appeared earlier in the literature. It was actually derived first in the 1988 discussion paper of Maskin and Moore (1999), but these authors did not introduce a specific name for such investments. MacLeod and Malcomson (1983) also studied such investments but they also did not come up with a name.

${ }^{6}$ For instance, with the introduction of the airbag systems car manufacturers initiated cooperations with plastic subcontractors to redesign the dashboard and bear the additional weight of the airbag.
} 
total duration of a Japanese buyer-supplier relationship is about ten years, this means that parties sign up to three different contracts by relationship. Third, these contractual arrangements provide room for renegotiation. Parties write basic renegotiable contracts establishing basic rules covering a range of items including price determination, payment, delivery, property rights, the supply of materials and quality issues (Nishiguchi, 1989). Finally, these contractual arrangements also promote cooperation. The typical contract sets a target price for each input produced. Buyers then cooperate and help suppliers to reach their targets (Cusumano and Takeishi, 1991; see also Nishiguchi, 1989). Therefore, overall Japanese firms seem to rely on partial commitment to their relationships and ex post bargaining to promote cooperation and joint investments.

Our result also echoes the literature on the value of partial commitment devices in other strategic and decision-theoretic environments. For instance, Colombo and Merzoni (2006, 2008) stress the value of partial commitment to a relationship in terms of the duration of contracts, while Amador et al. (2006) show the value of commitment devices that partially limit the freedom of choice with time-inconsistent preferences.

Our contribution is also related to Mclaren (1999), who distinguishes joint from autonomous investments. However, the latter are assumed to be not relationship specific. This implies parties can pay an additional fee to adapt the tailor-made input to an alternative buyer. Under this assumption, a nonrenegotiable fixed-price contract gives optimal incentives for autonomous investments, but not for joint work. Ex post bargaining is thus required to foster cooperation, as the supplier can always get the buyer to share the costs ex post. We assume instead that autonomous investments are relationship-specific and we find that a fixed-price contract is valuable to promote cooperation. ${ }^{7}$ However, this result is not necessarily in conflict with McLaren (1999). In fact, in both settings, the possibility of bargaining ex post fosters cooperation: although the present setting underlines the value of contracting as partial commitment,

\footnotetext{
${ }^{7}$ We demonstrate this result for both a renegotiable and non-renegotiable fixed-price contract. The latter implies that the default point value is zero. Since specific investments are sunk, the break-up of the contract would generate a loss of value and give optimal incentives to invest. As a result, it can be demonstrated that if parties credibly commit not to renegotiate their initial fixed-price contract, optimal cooperation can be reached, by implementing a game of messages which discloses the relevant information to a third party. See supplementary material on http://jose.desousa.univ.free.fr/research/sup.htm.
} 
contract incompleteness leaves room for renegotiation. ${ }^{8}$

The rest of the paper is organized as follows. In the next section, we present the model, a simple two-stage game between a buyer and a supplier. In section 3, we establish two benchmark outcomes to compare our results: the first-best and the ex post bargaining (without an initial contract). In section 4 , we show how a formal fixed-price contract arrangement may foster cooperation. Finally, in section 5 , we conclude.

\section{Model}

We consider a basic two-stage procurement model between a buyer $(b)$ and a supplier $(s)$. The buyer procures an input from the supplier. There are two simple ways of procuring the input: a formal or an informal arrangement.

In the formal arrangement, parties design a renegotiable fixed-price contract in the first stage and specify ex ante a fixed monetary transfer $(\bar{t} \in \Re)$ of the buyer to the supplier for a fixed quantity of input $\left(\bar{q} \in \Re_{+}\right)$. This initial allocation is enforceable by the court and ensures for the parties a status quo payoff. Contract terms are enforced in the second stage, unless they are renegotiated, in which case parties share ex post the surplus from renegotiation according to their bargaining strength.

In the informal arrangement, parties agree verbally, in the first stage, on the quantity of input without signing an initial contract. In the second stage, they bargain the terms of trade and determine the payment.

Whatever the arrangement, not contractible autonomous and joint investments are made simultaneously in the first stage. They are relationship-specific, which rules out outside options and the possibility of adapting the input for an alternative buyer (see above).

\section{Payoff functions and the nature of investments}

Let $v\left(q, j_{b}, j_{s}\right)$ denote the buyer's gross value of procuring the good $q \in \Re_{+}$ and $c\left(q, a, j_{b}, j_{s}\right)$ the supplier's gross monetary cost of producing $q$. Valuations are determined by relationship-specific investments. Let $a \in \Re_{+}$be the level (and cost) of autonomous investments made by the supplier. We first present the

\footnotetext{
${ }^{8} \mathrm{We}$ are grateful to a referee for suggesting this interpretation.
} 
assumptions made throughout this study before commenting in more details on $a, j_{b}$ and $j_{s}$.

Assumption $1 v$ and $c$ are continuously differentiable in all arguments.

Assumption $2 v\left(q, j_{b}, j_{s}\right) \geq 0$ is increasing in all arguments and strictly concave. For all $q>0$ and $\left(j_{b}, j_{s}\right) \in \Re_{+}^{2}$, it satisfies:

$$
\begin{gathered}
\lim _{q \rightarrow 0} v_{1}\left(q, j_{b}, j_{s}\right)=\infty, \quad \lim _{j_{b} \rightarrow 0} v_{2}\left(q, j_{b}, j_{s}\right)=\infty, \quad \lim _{j_{s} \rightarrow 0} v_{3}\left(q, j_{b}, j_{s}\right)=\infty \\
\lim _{q \rightarrow \infty} v_{1}\left(q, j_{b}, j_{s}\right)=0, \quad \lim _{j_{b} \rightarrow \infty} v_{2}\left(q, j_{b}, j_{s}\right)=0, \quad \lim _{j_{s} \rightarrow \infty} v_{3}\left(q, j_{b}, j_{s}\right)=0 .
\end{gathered}
$$

Assumption $3 c\left(q, a, j_{b}, j_{s}\right) \geq 0$ is increasing in $q$, decreasing in investments and strictly convex. For all $q>0$ and $\left(a, j_{b}, j_{s}\right) \in \Re_{+}^{3}$, it satisfies:

$$
\begin{aligned}
& \lim _{q \rightarrow 0} c_{1}\left(q, a, j_{b}, j_{s}\right)=0 \quad \lim _{a \rightarrow 0} c_{2}\left(q, a, j_{b}, j_{s}\right)=-\infty \\
& \lim _{j_{b} \rightarrow 0} c_{3}\left(q, a, j_{b}, j_{s}\right)=-\infty \lim _{j_{s} \rightarrow 0} c_{4}\left(q, a, j_{b}, j_{s}\right)=-\infty . \\
& \lim _{q \rightarrow \infty} c_{1}\left(q, a, j_{b}, j_{s}\right)=\infty \quad \lim _{a \rightarrow \infty} c_{2}\left(q, a, j_{b}, j_{s}\right)=0, \\
& \lim _{j_{b} \rightarrow \infty} c_{3}\left(q, a, j_{b}, j_{s}\right)=0 \quad \lim _{j_{s} \rightarrow \infty} c_{4}\left(q, a, j_{b}, j_{s}\right)=0 .
\end{aligned}
$$

Concavity and convexity of assumptions 2 and 3 imply decreasing returns for both parties.

\section{Assumption 4}

$$
\forall\left(j_{b}, j_{s}\right) \in \Re_{+}^{2} v\left(0, j_{b}, j_{s}\right)=0, \quad \text { and } \quad \forall\left(a, j_{b}, j_{s}\right) \in \Re_{+}^{3} c\left(0, a, j_{b}, j_{s}\right)=0 .
$$

Assumption (4) says that when $q=0$ both valuations do no depend on the level of investments. Since there is no outside market for investments, this assumption suggests that investments are relationship-specific (Chung, 1991: 1034).

Assumption 5 The cross derivatives of $v\left(q, j_{b}, j_{s}\right)$ and $c\left(q, a, j_{b}, j_{s}\right)$ satisfy $v_{i \ell}\left(q, j_{b}, j_{s}\right)>0$ and $c_{i \ell}\left(q, a, j_{b}, j_{s}\right)<0$ for all $i \neq \ell$.

Assumption (5) says that investments are complementary.

\section{Assumption 6}

$$
v_{2}\left(q, j_{b}, 0\right)=0, \text { and } c_{3}\left(q, a, 0, j_{s}\right)=0
$$


Assumption (6) stipulates that the marginal return of joint investments is null when only one party is contributing. This assumption departs from other related structures of investments in the literature. Thus, our structure would be equivalent to the Edlin and Reichelstein (1996)'s one-sided investment structure if we dropped $j_{b}$ and $j_{s}$ and only retained the autonomous investment $a$, which is a 'selfish' investment directly benefiting only to the supplier through its valuation $c$. Following the terminology coined by Che and Hausch (1999), a can also be purely cooperative or partly cooperative (i.e., hybrid). Recall that $a$ is partly cooperative when it affects both valuations $c$ and $v$ and purely cooperative when it affects only the buyer's valuation $v$. However, Che and Hausch (1999)'s terminology may be somewhat misleading since "cooperative" has nothing to do with cooperative behavior. There is no joint work. Cooperation is achieved independently from the other party and $a$ has an effect even if the other decides not to invest. In our setting, $a$ is a selfish investment and cooperation is achieved through additional joint investments $j_{b}$ and $j_{s}$ affecting both valuations. Following assumptions (5) and (6), joint investments are complementary and require an explicit cooperation between the parties: one party investment generates benefits only if the other party also invests. Using this structure of investments, we study the value of partial commitment to solve the hold-up problem for joint investments.

\section{Benchmark outcomes}

We establish two useful benchmarks, the first-best and the no-contracting outcome, with which later results about contracting may be compared.

\subsection{The first-best outcome}

The first-best corresponds to the solution of the integrated firm program, which internalizes the effects of investment. The maximization program of the integrated firm is separable. In a first step, we determine the optimal quantity $\left(q^{*}\right)$ given the investment levels. Then, we determine the investment levels given the optimal quantity.

Let $\Pi$ denote the maximum gross joint surplus, such that:

$$
\Pi\left(a, j_{b}, j_{s}\right)=\max _{q \geq 0}\left[v\left(q, j_{b}, j_{s}\right)-c\left(q, a, j_{b}, j_{s}\right)\right]
$$


According to the optimality condition $v_{1}=c_{1}$, we obtain

$$
q^{*}=q^{*}\left(a, j_{b}, j_{s}\right)
$$

the quantity equalizing the marginal benefit to the marginal cost, therefore

$$
\Pi\left(a, j_{b}, j_{s}\right)=v\left(q^{*}, j_{b}, j_{s}\right)-c\left(q^{*}, a, j_{b}, j_{s}\right) .
$$

The net joint surplus of investments $S\left(a, j_{b}, j_{s}\right)$ is given by:

$$
S\left(a, j_{b}, j_{s}\right)=\Pi\left(a, j_{b}, j_{s}\right)-a-j_{b}-j_{s},
$$

with $\Pi\left(a, j_{b}, j_{s}\right)$ strictly concave since $v($.$) is concave and c($.$) convex. The efficient$ investments are such that $\left(a^{*}, j_{b}^{*}, j_{s}^{*}\right) \in \arg \max _{a, j_{b}, j_{s}} \Pi\left(a, j_{b}, j_{s}\right)-a-j_{b}-j_{s}$.

Given the assumptions on $v$ and $c,\left(a^{*}, j_{b}^{*}, j_{s}^{*}\right)$ are unique and satisfy a system of first-order conditions (FOCs):

$$
\begin{aligned}
& \Pi_{1}\left(a^{*}, j_{b}^{*}, j_{s}^{*}\right)-1=0 \\
& \Pi_{2}\left(a^{*}, j_{b}^{*}, j_{s}^{*}\right)-1=0 \\
& \Pi_{3}\left(a^{*}, j_{b}^{*}, j_{s}^{*}\right)-1=0
\end{aligned}
$$

\subsection{The (informal) no-contracting outcome}

We now consider the no-contracting game. Let us recall the sequence of events. Ex ante, parties agree verbally, without a prior contract, that the supplier will produce the input. Ex post, parties share the surplus according to their exogenous bargaining positions. ${ }^{9}$ The optimal quantity $q^{*} \in \Re_{+}$and the monetary transfer $t \in \Re$ are determined in the second stage, while investments are realized in the first stage.

At the second stage, the negotiation outcome on $q$ and $t$ is solution of a Nash bargaining process, with $\mu \in[0,1]$ the supplier's bargaining strength:

$$
\max _{t, q}\left[v\left(q, j_{b}, j_{s}\right)-t\right]^{1-\mu}\left[t-c\left(q, a, j_{b}, j_{s}\right)\right]^{\mu} .
$$

Therefore $q^{*}=q^{*}\left(a, j_{b}, j_{s}\right)$, is implicitly determined by

$$
v_{1}\left(q^{*}, j_{b}, j_{s}\right)=c_{1}\left(q^{*}, a, j_{b}, j_{s}\right)
$$

and

$$
t\left(a, j_{b}, j_{s}\right)=(1-\mu) c\left(q^{*}, a, j_{b}, j_{s}\right)+\mu v\left(q^{*}, j_{b}, j_{s}\right) .
$$

At the first stage, the buyer and the supplier maximize their surplus:

\footnotetext{
${ }^{9}$ In an incomplete contract framework, it does not seem reasonable to assume that bargaining positions may be endogenously determined ex ante and enforced.
} 
- for the buyer:

$$
U_{b}=v\left(q^{*}, j_{b}, j_{s}\right)-(1-\mu) c\left(q^{*}, a, j_{b}, j_{s}\right)-\mu v\left(q^{*}, j_{b}, j_{s}\right)-j_{b}
$$

- for the supplier:

$$
U_{s}=(1-\mu) c\left(q^{*}, a, j_{b}, j_{s}\right)+\mu v\left(q^{*}, j_{b}, j_{s}\right)-c\left(q^{*}, a, j_{b}, j_{s}\right)-a-j_{s} .
$$

Given the optimal produced quantity $q^{*}$, determined by equation (1) in both the first-best and the no-contracting outcome, we rewrite the above surplus using $\Pi\left(a, j_{b}, j_{s}\right)$. It follows that parties choose the investment levels of the nocontracting outcome $\left(\widehat{a}, \widehat{\jmath}_{b}, \widehat{\jmath}_{s}\right)$ satisfying

$$
\begin{aligned}
& \left(\widehat{\jmath}_{b}\right) \in \arg \max _{j_{b}}(1-\mu) \Pi\left(a, j_{b}, j_{s}\right)-j_{b}, \\
& \left(\widehat{a}, \widehat{\jmath}_{s}\right) \in \arg \max _{a, j_{s}} \mu \Pi\left(a, j_{b}, j_{s}\right)-a-j_{s},
\end{aligned}
$$

and the following system of FOCs:

$$
\begin{aligned}
& \frac{\partial U_{b}}{\partial j_{b}}=(1-\mu) \Pi_{2}\left(\widehat{a}, \widehat{\jmath}_{b}, \widehat{j}_{s}\right)-1=0 \\
& \frac{\partial U_{s}}{\partial a}=\mu \Pi_{1}\left(\widehat{a}, \widehat{\jmath}_{b}, \widehat{\jmath}_{s}\right)-1=0 \\
& \frac{\partial U_{s}}{\partial j_{s}}=\mu \Pi_{3}\left(\widehat{a}, \widehat{\jmath}_{b}, \widehat{\jmath}_{s}\right)-1=0
\end{aligned}
$$

Since $\mu \in[0,1]$, efficiency cannot be achieved. This may be explained as follows. Investments are made ex ante, while the surplus is shared ex post according to the bargaining positions. The payment $t$ is determined independently of the investments made; therefore, externalities cannot be internalized.

What are the consequences of such an inefficiency? Given the concavity of $\Pi\left(a, j_{b}, j_{s}\right)$, the parties will invest less than the socially optimal level.

Proposition 1 Under assumptions (1) to (6), the absence of contracting prior investing in specific assets induces under-investments, such that: $\widehat{a}<a^{*}, \widehat{\jmath}_{b}<j_{b}^{*}$ and $\widehat{\jmath}_{s}<j_{s}^{*}$.

Proof See appendix (A). 


\section{Contracting and cooperation}

We have seen that parties do not reach efficiency by simply bargaining ex post the terms of trade without a prior contract. Now suppose that parties sign a simple renegotiable fixed-price contract that specifies a fixed monetary transfer $(\bar{t} \in \Re)$ of the buyer to the supplier for a fixed quantity of goods $\left(\bar{q} \in \Re_{+}\right)$. Two questions arise. First, does the signing of this simple renegotiable contract make it possible to achieve efficiency? Second, failing that, does contracting offer a better outcome than the no-contracting game? If not, the contract has no value, and the optimal contract is the 'no contract.'

\subsection{The contracting outcome}

With regard to the first question, we find in a simple way that contracting does not make it possible to reach the first-best. This is not very surprising and can be shown formally.

Let first define the (gross) renegotiation surplus $(R S)$, available ex post as:

$$
R S=\Pi\left(a, j_{b}, j_{s}\right)-\left[v\left(\bar{q}, j_{b}, j_{s}\right)-c\left(\bar{q}, a, j_{b}, j_{s}\right)\right] .
$$

At the second stage, we assume a Nash bargaining process on $q$ and $t$, solution of

$\max _{t, q}\left[v\left(q, j_{b}, j_{s}\right)-t-v\left(\bar{q}, j_{b}, j_{s}\right)+\bar{t}\right]^{1-\mu} \times\left[t-c\left(q, a, j_{b}, j_{s}\right)-\bar{t}+c\left(\bar{q}, a, j_{b}, j_{s}\right)\right]^{\mu}$.

We obtain $q^{*}=q^{*}\left(a, j_{b}, j_{s}\right)$ implicitly determined by

$$
v_{1}\left(q^{*}, j_{b}, j_{s}\right)=c_{1}\left(q^{*}, a, j_{b}, j_{s}\right)
$$

and

$t\left(a, j_{b}, j_{s}\right)=(1-\mu)\left[c\left(q^{*}, a, j_{b}, j_{s}\right)-c\left(\bar{q}, a, j_{b}, j_{s}\right)\right]+\mu\left[v\left(q^{*}, j_{b}, j_{s}\right)-v\left(\bar{q}, j_{b}, j_{s}\right)\right]+\bar{t}$

The first stage objectives to be maximized are:

- for the buyer:

$$
U_{b}=\underbrace{v\left(\bar{q}, j_{b}, j_{s}\right)-\bar{t}}_{A}+\underbrace{(1-\mu) R S}_{B}-j_{b} .
$$

$(A)$ is the buyer's payoff given by the initial contract. It represents the buyer's status quo position. $(B)$ is the payoff from the renegotiation process, depending on the buyer's bargaining strength $(1-\mu)$. 
- for the supplier:

$$
U_{s}=\underbrace{\bar{t}-c\left(\bar{q}, a, j_{b}, j_{s}\right)}_{C}+\underbrace{\mu R S}_{D}-a-j_{s} .
$$

$(C)$ is the supplier's cost given by the initial contract. It represents the supplier's status quo position. $(D)$ is the payoff from the renegotiation process, depending on the supplier's bargaining strength $\mu$.

Parties make the investment levels of the contracting outcome $\left(\widetilde{a}, \widetilde{\jmath}_{b}, \widetilde{\jmath}_{s}\right)$, satisfying

$$
\begin{aligned}
& \left(\widetilde{\jmath}_{b}\right) \in \arg \max _{j_{b}} v\left(\bar{q}, j_{b}, j_{s}\right)-\bar{t}+(1-\mu) R S-j_{b}, \\
& \left(\widetilde{a}, \widetilde{\jmath}_{s}\right) \in \arg \max _{a, j_{s}} \bar{t}-c\left(\bar{q}, a, j_{b}, j_{s}\right)+\mu R S-a-j_{s} .
\end{aligned}
$$

and the following system of first-order conditions:

$$
\begin{aligned}
& \frac{\partial U_{b}}{\partial j_{b}}=\mu v_{2}\left(\bar{q}, \widetilde{\jmath}_{b}, \widetilde{\jmath}_{s}\right)+(1-\mu) c_{3}\left(\bar{q}, \widetilde{a}, \widetilde{\jmath}_{b}, \widetilde{\jmath}_{s}\right)+(1-\mu) \Pi_{2}\left(\widetilde{a}, \widetilde{\jmath}_{b}, \widetilde{\jmath}_{s}\right)-1=0, \\
& \frac{\partial U_{s}}{\partial a}=-(1-\mu) c_{2}\left(\bar{q}, \widetilde{a}, \widetilde{\jmath}_{b}, \widetilde{\jmath}_{s}\right)+\mu \Pi_{1}\left(\widetilde{a}, \widetilde{\jmath}_{b}, \widetilde{\jmath}_{s}\right)-1=0, \\
& \frac{\partial U_{s}}{\partial j_{s}}=-\mu v_{3}\left(\bar{q}, \widetilde{\jmath}_{b}, \widetilde{\jmath}_{s}\right)-(1-\mu) c_{4}\left(\bar{q}, \widetilde{a}, \widetilde{\jmath}_{b}, \widetilde{\jmath}_{s}\right)+\mu \Pi_{3}\left(\widetilde{a}, \widetilde{\jmath}_{b}, \widetilde{\jmath}_{s}\right)-1=0 .
\end{aligned}
$$

Since $\mu \in[0,1]$, it is not possible to implement the first-best outcome. This implies that contracting with renegotiation does not make it possible to achieve efficiency.

\subsection{Contracting or no-contracting?}

We fail to achieve efficiency with contracting. However, we wonder whether writing a contract is valuable, that is, if contracting offers a better outcome than no-contracting. A simple comparison of the no-contracting FOCs (5 - 7) with the contracting FOCs $(8-10)$ shows that there is no obvious result regarding the improving effect of contracting.

The bargaining position $(\mu)$ plays an important role in deriving more precise results about the comparison between contracting and no-contracting outcomes. Before proceeding to the formal comparison, we consider some critical values of the parameter $\mu$ and two useful lemmas. Then we work out the comparison.

Let first define the set $\mathcal{A}$ :

$$
\mathcal{A}=\left\{k \in[0,1] / k v_{3}\left(q, j_{b}, j_{s}\right)+(1-k) c_{4}\left(q, a, j_{b}, j_{s}\right) \leq 0, \forall q, a, j_{b}, j_{s}\right\} .
$$


Let $\bar{\mu}=\sup \mathcal{A}$. This number exists; if $k=0$, the above inequality, used to define $\sup \mathcal{A}$, reduces to $c_{4}\left(q, a, j_{b}, j_{s}\right) \leq 0$, which is satisfied $\forall q, a, j_{b}, j_{s}$. The following useful lemma can now be stated.

Lemma 1 If $\mu<\bar{\mu}$, then: $\mu v_{3}\left(q, j_{b}, j_{s}\right)+(1-\mu) c_{4}\left(q, a, j_{b}, j_{s}\right) \leq 0, \forall q, a, j_{b}, j_{s}$.

Proof See appendix (B).

We now define one other critical value of $\mu$. Consider the set $\mathcal{C}$ :

$$
\mathcal{C}=\left\{k \in[0,1] / k v_{2}\left(q, j_{b}, j_{s}\right)+(1-k) c_{3}\left(q, a, j_{b}, j_{s}\right) \geq 0, \forall q, a, j_{b}, j_{s}\right\} .
$$

Let define $\underline{\mu}=\inf \mathcal{C}$. This number again exists; if $k=1$, the inequality, used to define $\mathcal{C}$, becomes $v_{3}\left(q, j_{b}, j_{s}\right) \geq 0$, which is satisfied $\forall q, j_{b}, j_{s}$. A second useful lemma can now be stated.

Lemma 2 If $\mu>\underline{\mu}$, then: $\mu v_{2}\left(q, j_{b}, j_{s}\right)+(1-\mu) c_{3}\left(q, a, j_{b}, j_{s}\right) \geq 0, \forall q, a, j_{b}, j_{s}$.

Proof The proof is the same as the one of Lemma 1. \|

Using Lemmas 1 and 2, we now determine the value of the simple fixed-price contract in comparison with the no-contracting outcome:

Proposition 2 Suppose that assumptions (1) to (6) hold. If $\underline{\mu}<\mu<\bar{\mu}$, then the no-contracting outcome generates a general under-investment in comparison with the contracting outcome. It follows that $\widehat{a}<\widetilde{a}, \widehat{\jmath}_{b}<\widetilde{\jmath}_{b}$ and $\widehat{\jmath}_{s}<\widetilde{\jmath}_{s}$.

Proof See appendix (C).

The results of propositions (1) and (2) state that no-contracting leads to under-investments compared to both the first-best and the contracting solutions. However, these propositions do not discriminate between contracting and nocontracting outcomes in terms of welfare. Contracting would be welfare improving, if we could prove that (suboptimal) contracting investments are lower than the first-best ones, given that over-investment is also a suboptimal solution. The comparison of the first-best and the contracting outcomes depends on the value of $\bar{q}$ fixed in the contract. We have the following proposition.

Proposition 3 Suppose that assumptions (1) to (6) hold. If $\bar{q}$ is such that $\bar{q}<$ $q^{*}\left(\widetilde{a}, \widetilde{\jmath}_{b}, \widetilde{\jmath}_{s}\right)$, then the contracting outcome generates a general under-investment in comparison with the first-best. It follows that $\widetilde{a}<a^{*}, \widetilde{\jmath}_{b}<\jmath_{b}^{*}$ and $\widetilde{\jmath}_{s}<\jmath_{s}^{*}$. 
Proof See appendix (D).

The contracting investment levels $\left(\widetilde{a}, \widetilde{\jmath}_{b}, \widetilde{\jmath}_{s}\right)$ depend on the value of $\bar{q}$ (see equations 8-10). It turns out that if $\bar{q}$ is such that $\bar{q}<q^{*}\left(\widetilde{a}, \widetilde{\jmath}_{b}, \widetilde{\jmath}_{s}\right)$, then investment levels in the contracting case are lower than in the first-best outcome.

The above proposition can be usefully supplemented by a corollary stating the existence of a critical value for $\bar{q}$.

Corollary 1 For a given $\mu$, suppose there exists a value $\bar{q}$ such that the resulting contracting investment levels satisfy : $\bar{q}=q^{*}\left(\widetilde{a}, \widetilde{j}_{s}, \widetilde{j}_{b}\right)$. The contracting investment levels are then independent of $\mu$.

Proof See appendix (E).

The contracting investment levels are function of $\mu$ and $\bar{q}$. Thus, for each value of $\mu$, it should exist a value of $\bar{q}$ compatible with $\bar{q}=q^{*}\left(\widetilde{a}, \widetilde{j}_{s}, \widetilde{j}_{b}\right)$. The above corollary states that the value of $\bar{q}$ ensuring that $\bar{q}=q^{*}\left(\widetilde{a}, \widetilde{j}_{s}, \widetilde{j}_{b}\right)$ is in fact independent of $\mu$.

\subsection{Numerical investigations}

The two preceding propositions suggest that parameters $\mu$ and $\bar{q}$ play a crucial role in the comparison of the different outcomes (in terms of investments, produced quantities and total surplus). Unfortunately, it is not possible first to provide precise analytical results enabling the discrimination between contracting and no-contracting outcomes, and second, to perform surplus comparisons. We conduct instead numerical investigations to provide insight into the influence of parameters $\mu$ and $\bar{q}$ on the model outcomes.

The buyer's value and the supplier's cost functions are defined as follows:

$$
\begin{gathered}
v\left(q, \jmath_{b}, \jmath_{s}\right)=B_{0} q^{b_{0}}\left[\left(\jmath_{b}^{\beta_{2}} \jmath_{s}^{\beta_{2}}\right)^{\theta}\right]^{b_{1}} \\
c\left(q, a, \jmath_{b}, \jmath_{s}\right)==A_{0} q^{a_{0}}\left[\left(\alpha_{0} a^{-\frac{1-\sigma}{\sigma}}+\alpha_{1} \jmath_{b}^{-\frac{1-\sigma}{\sigma}}+\alpha_{2} \jmath_{s}^{-\frac{1-\sigma}{\sigma}}\right)^{-\nu \frac{\sigma}{1-\sigma}}\right]^{-a_{1}}
\end{gathered}
$$

with $B_{0}>0, b_{0}, b_{1}>0, b_{0}+b_{1}<1, \beta_{1}, \beta_{2}>0, \beta_{1}+\beta_{2}=1,0<\theta<1, A_{0}>0$, $a_{0}>1, a_{1}>0, a_{0}-a_{1}>1, \sigma>0,0<\nu<1, \alpha_{0}, \alpha_{1}, \alpha_{2}>0$ and $\alpha_{0}+\alpha_{1}+\alpha_{2}=1$. Numerical investigations are made using the following benchmark calibration: 
Table 1: Benchmark calibrations

\begin{tabular}{cccccccc}
\hline \hline & \multicolumn{7}{c}{ Buyer's value } \\
\cline { 2 - 7 } & $B_{0}$ & $b_{0}$ & $b_{1}$ & $\beta_{1}$ & $\beta_{2}$ & $\theta$ & \\
\cline { 2 - 7 } & 10 & 0.5 & 0.3 & 0.8 & 0.2 & 0.8 & \\
\hline \hline \multicolumn{7}{c}{ Supplier's cost } \\
\hline$A_{0}$ & $a_{0}$ & $a_{1}$ & $\alpha_{0}$ & $\alpha_{1}$ & $\alpha_{2}$ & $\sigma$ & $\nu$ \\
\hline 10 & 2 & 0.8 & 0.4 & 0.2 & 0.4 & 0.6 & 0.8 \\
\hline \hline
\end{tabular}

Under this parametrization, assumptions (1-6) are satisfied. ${ }^{10}$ First best results reported in Table (2) are graphically represented in Figures (1) and (2).

Table 2: First best results

\begin{tabular}{ccccc}
\hline \hline$q^{*}$ & $a^{*}$ & $J_{b}^{*}$ & $J_{s}^{*}$ & $S^{*}$ \\
\hline 0.3252 & 0.4530 & 1.2317 & 0.6391 & 2.0334 \\
\hline \hline
\end{tabular}

Let's first study the impact of a variation of the supplier's bargaining strength $\mu$ on the investment levels, the produced quantities and the total surplus, under three cases: first-best, no-contracting and contracting. Several values of the fixed quantity $\bar{q}$ are considered for the contracting case. ${ }^{11}$

Figure (1) provides a representation in terms of produced quantities and total surplus. Regarding produced quantities $(q)$, the numerical investigations suggest that $q$ is sensitive in the contracting case to the value of the fixed quantity $\bar{q}$. More precisely, $q$ increases as $\bar{q}$ grows. Results also show that the contracting produced quantities are always above the no-contracting ones and may be above the first best ones for high values of $\bar{q}{ }^{12}$ We identify a critical value of $\bar{q}$, satisfying $\bar{q}=q^{*}\left(\widetilde{a}, \widetilde{j}_{b}, \widetilde{j}_{s}\right)$, which is roughly 0.24 . If $\bar{q}$ is less than this value, the contracting produced quantity is increasing in $\mu$. The converse applies if $\bar{q}$ is greater than the critical value. Finally, if $\bar{q}$ is equal to the critical value, the contacting produced quantities (and investment levels) are higher than the nocontracting values, lower than the first-best, and independent of the supplier's bargaining strength (consistently with corollary 1 ).

Concerning total surplus, our simulations in Figure (1) show that the nocontracting case surplus is significantly smaller than the first-best. However,

\footnotetext{
${ }^{10}$ Assumptions (5) and (6) about the supplier's cost function are satisfied if $\nu a_{1}-\frac{1-\sigma}{\sigma}<0$.

${ }^{11}$ The contracting case with $\bar{q}=0$ is similar to the no-contracting case.

${ }^{12}$ This is the case when $\bar{q}$ is about 1.5 times the value of the quantity produced in the fist-best case (see table 2).
} 

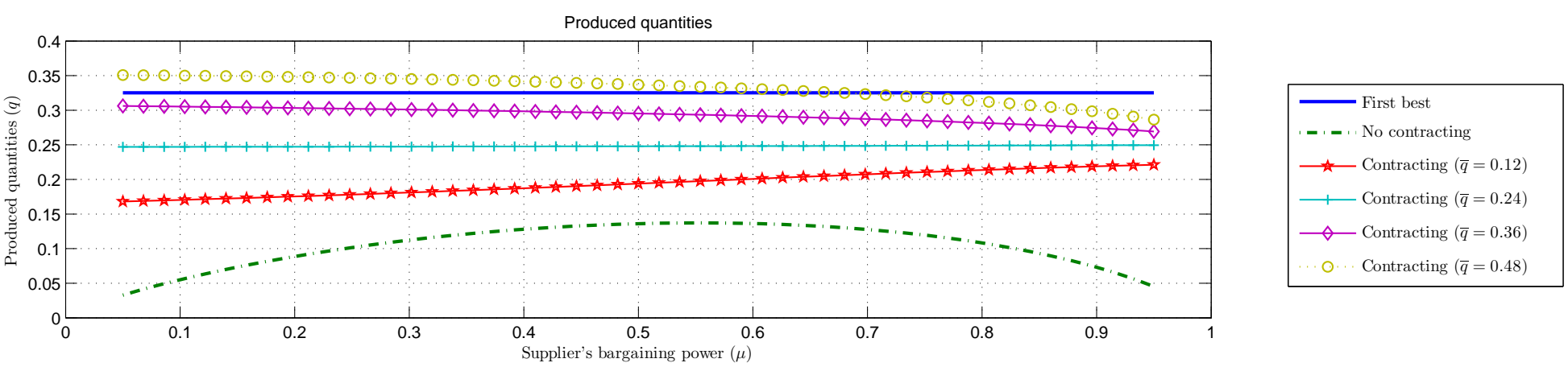

Total surplus

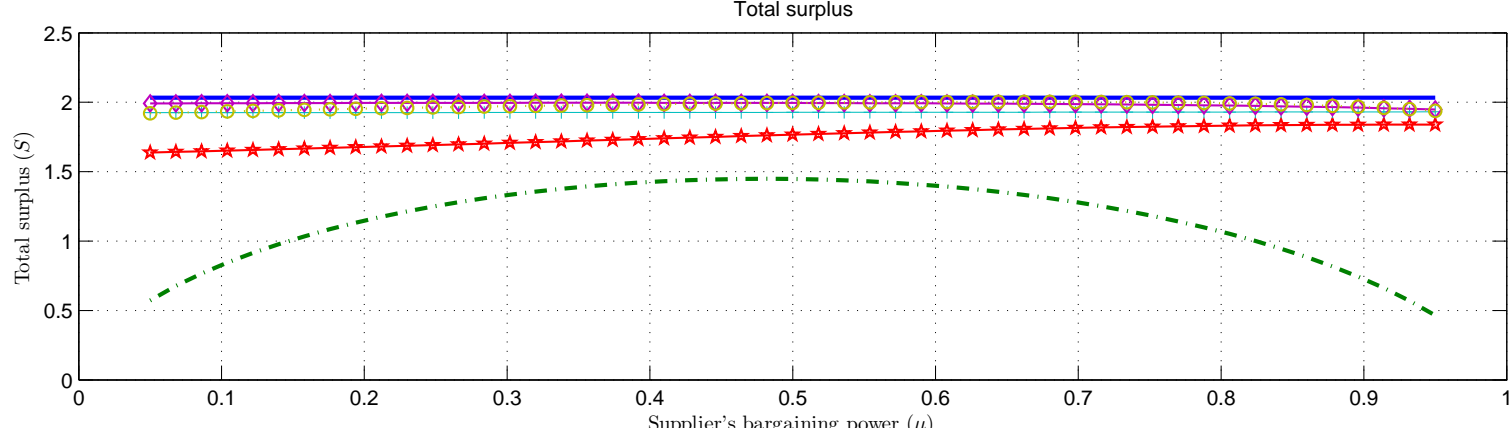

- First best
$\square \quad$ Contracting $(\bar{q}=0.12)$
$\square \quad$ Contracting $(\bar{q}=0.24)$
$\square \quad$ Contracting $(\bar{q}=0.36)$
$\square \quad$ Contracting $(\bar{q}=0.48)$


contracting allows significant improvement. The total surplus increases as $\bar{q}$ grows. Moreover, our numerical investigations suggest there exists values of $\mu$ and $\bar{q}$ that maximize the contracting surplus. Solving a second-best problem, ${ }^{13}$ we determine the values of $\mu^{*}$ and $\bar{q}^{*}$ maximizing the contracting total surplus. Results reported in Table 3 suggest that contracting may significantly improve the allocation. If $\mu$ and $\bar{q}$ are appropriately set, the contracting surplus is very close to the first-best (it is less by $1.44 \%$ ).

Table 3: Contracting results $\left(\bar{q}^{*}=0.4571\right.$ and $\left.\mu^{*}=0.6144\right)$

\begin{tabular}{ccccc}
\hline \hline$\widetilde{q}$ & $\widetilde{a}$ & $\widetilde{\jmath}_{b}$ & $\widetilde{\jmath}_{s}$ & $\widetilde{S}$ \\
\hline 0.3206 & 0.5436 & 1.1694 & 0.5259 & 2.0042 \\
\hline \hline
\end{tabular}

A principal function of the fixed-price contract is to fix an initial quantity of input $\left(\bar{q} \in \Re_{+}\right)$. Then, for a given $\mu$, how can we determine the value of $\bar{q}$ maximizing the contracting total surplus? To begin with, suppose that investments are such that $v_{3}\left(q, j_{b}, j_{s}\right)=c_{3}\left(q, a, j_{b}, j_{s}\right)=0$. In that case, it can easily be checked that a contract setting $\bar{q}=q\left(a^{*}, j_{b}^{*}, j_{s}^{*}\right)$ implements the first-best, which is consistent with Edlin and Reichelstein (1995). However, this is no longer true with joint investments and only a second-best can be achieved. Figure (2) depicts the second-best quantities and surplus. ${ }^{14}$ If the second best value of $\bar{q}$ is chosen, the surplus loss with respect to the first best values roughly varies from $1.4 \%$ to $4.2 \%$. In contrast, in the no-contracting case, the minimum loss surplus is about $30 \%$. Thus, implementing the second-best significantly improves efficiency.

We also provide results when $\bar{q}$ is set at specific values of interest: the firstbest $\left(q^{*}=0.325\right)$ and the critical value $(\bar{q}=0.24)$. The total surplus of the contracting outcome is again significantly higher than in the no-contracting case. In particular, choosing $\bar{q}=q^{*}$ induces a surplus loss varying from $2.3 \%$ to $4.3 \%$. In other words, choosing the first best value $\bar{q}=q^{*}$, in a setting with joint investments, significantly improves efficiency (compared to no-contracting). ${ }^{15}$

In our framework, optimality is not attainable for two reasons. First, parties are linked by a relationship specific-investment. The good is not traded on a competitive market and partners have no outside options. So, inefficient investment

\footnotetext{
${ }^{13}$ We determine the values of $\mu$ and $\bar{q}$ maximizing the total surplus subject to the set of constraints constituted by equations (8)-(10).

${ }^{14}$ For a given value of $\mu$, we determine the values of $\bar{q}$ maximizing the total surplus subject to the set of constraints (8)-(10).

${ }^{15}$ Note that without joint investment optimality is restored when $\bar{q}=q^{*}$.
} 
Produced quantities - Second best

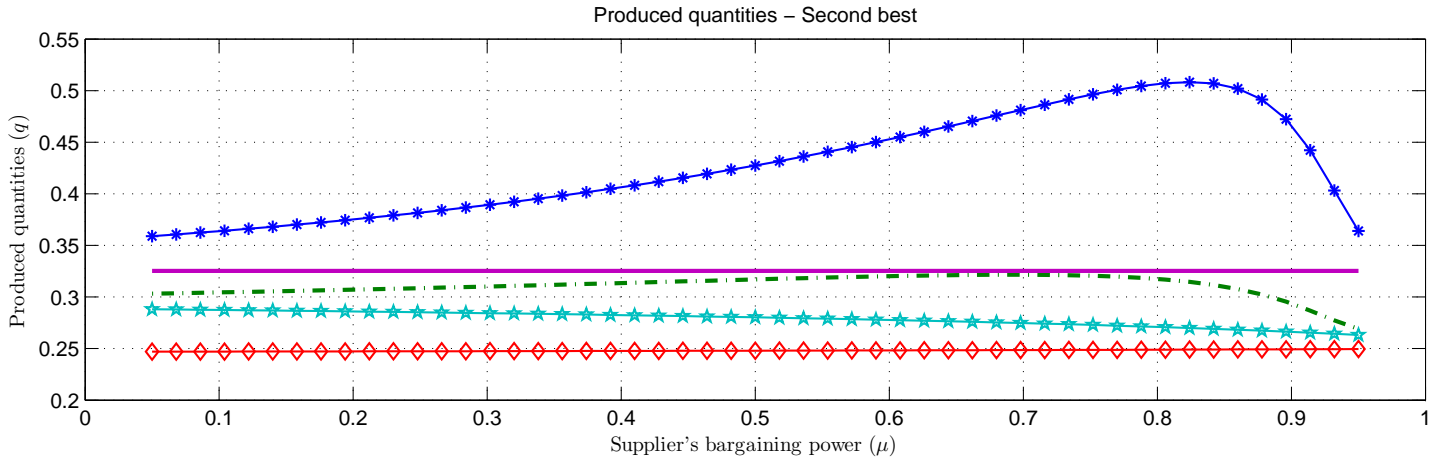

* $\bar{q}$ Second best
$\square \quad$ Contracting $(\bar{q}$ Second best $)$
$\square \quad$ Contracting $(\bar{q}=0.24)$
$\square \quad$ First best

の

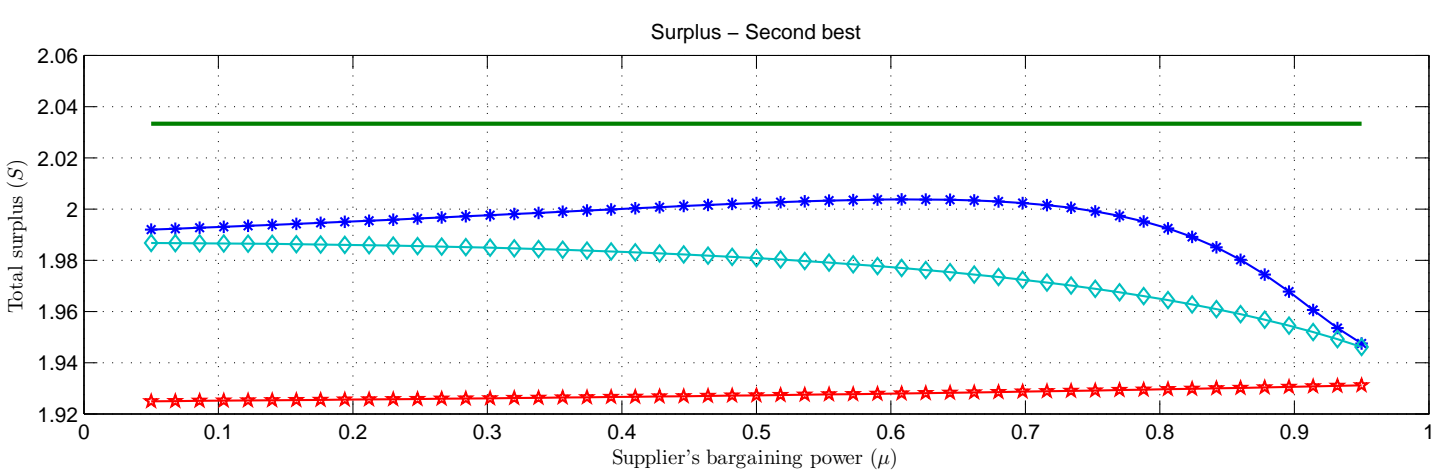


occurs due to a traditional hold-up problem. Each party under-invests because it receives only a fraction of the marginal return of its investment. The private marginal return of investment is thus lower than the social marginal return.

Second, there are joint investments (and thus investment externalities). The buyer's value $v$ and the seller's cost $c$ are both influenced by $j_{b}$ and $j_{s}$. Thus, the investment of one party has a positive effect on the marginal value of the other party (supermodularity assumption). In the no-contracting case, supermodularity leads parties to under-invest and optimality can not be achieved. Are parties made better off by contracting and renegotiating? The contracting game is also altered due to joint investments. However, our numerical investigations suggest that renegotiation may improve the total surplus. Contracting (equations (8) (10) ) induces a modification of the marginal return of investment that comprises two terms. First, under contracting, an investment increases the status quo position of the investor. But, second, if this investment is joint, this also increases the status quo payoff of the trading partner, which weakens the investor's position. The net gain obtained by the investor is a weighted mean (depending of the bargaining power) of these two effects. An increase in the investor's bargaining power tends to reduce its net gain through a reduction of its status quo position and an increase in the trading partner's payoff. So, a higher bargaining power leads to a smaller gain from renegotiation. In other words, a party has little interest in renegotiating if it has a strong bargaining power.

What are the effects of the fixed quantity $\bar{q}$ on the renegotiation stage? We discuss now how changes in $\bar{q}$ provide incentives to improve the total surplus. Recall that if $\bar{q}=0$, the no-contacting solution is attained, while increasing $\bar{q}$ improves the status quo position of the investors. ${ }^{16}$ However, in case of joint investments, the trading partner payoff is also improved, which leads to a reduction of the bargaining position of the investor. It follows that increasing $\bar{q}$ has an ambiguous effect on the bargaining position of the investor (which is not the case with an autonomous investment).

To sum up, $\bar{q}$ and $\mu$ may have ambiguous effects that can not be evaluated analytically. Our numerical investigations however show that writing a contract may be valuable and that the values of $\bar{q}$ and $\mu$ matter. As a whole, starting from an under-investment situation (no-contracting or $\bar{q}=0$ ), increasing $\bar{q}$ allows to improve the total surplus because it increases the investors' bargaining position.

\footnotetext{
${ }^{16}$ Recall that $v_{1 i}>0$ and $c_{1 i}<0$ for all $i>1$.
} 


\section{Conclusion}

In this paper, we analyze two simple ways in which the input could be procured: (1) a renegotiable fixed-price contract and (2) an ex post bargaining of the terms of trade without a prior contract. We found that arrangements fail both to achieve efficiency and to provide an incentive for optimal joint investments. A direct implication of this result is that a process of vertical integration, with a unified direction, provides optimal incentives to cooperate.

We also aimed to compare the contracting and the no-contracting solutions. We found that contracting induces larger autonomous and joint investments compared to not contracting. Moreover, our formal analysis suggests that the supplier's bargaining strength and the fixed quantity of input play a crucial role in the comparison of the different outcomes (in terms of investments, produced quantities and total surplus). Formally, contracting is welfare-improving for values of the fixed quantity lower than a given threshold. Numerically, we have shown that the contracting surplus is very close to the first-best one for appropriate values of the supplier's bargaining strength and the fixed quantity of input. Therefore, ex post bargaining is not always needed to promote cooperation. This is in line with Japanese procurement practices, where firms rely both on partial commitment to their relationships and ex post bargaining to promote cooperation

\section{References}

Aghion, Philippe, Mathias Dewatripont and Patrick Rey (1994), 'Renegotiation design with unverifiable information', Econometrica 62(2), 257-282.

Amador, Manuel, Werning Ivan and Angeletos George-Marios (2006), 'Commitment vs. flexibility', Econometrica 74(2), 365-396.

Aoki, Masahiko (1988), Information, Incentives, and Bargaining in the Japanese Economy, Cambridge University Press, New York.

Asanuma, Banri (1985a), 'The contractual framework for parts supply in the Japanese automotive industry', Japanese Economic Studies 13(4), 54-78.

Asanuma, Banri (1985b), 'The organization of parts purchases in the Japanese automotive industry', Japanese Economic Studies 13(4), 32-53.

Asanuma, Banri (1989), 'Manufacturer-supplier relationships in Japan and the concept of relation-specific skill', Journal of the Japanese and International Economies 3(1), 1-30. 
Chung, Tai-Yeong (1991), 'Incomplete contracts, specific investments and risk sharing', Review of Economic Studies 58, 1031-1042.

Colombo, Ferdinando and Guido Merzoni (2006), 'In praise of rigidity. the bright side of long-term contracts in repeated trust games', Journal of Economic Behavior and Organization 59, 349-373.

Colombo, Ferdinando and Guido Merzoni (2008), 'For how long to tie your hands? stable relationships in an unstable environment', Journal of Economics 95, 93120 .

Cusumano, M.A. and A. Takeishi (1991), 'Supplier relations and management: a survey of Japanese, Japanese-transplant, and US auto plants', Strategic Management Journal 12(8).

Edlin, Aaron and Stefan Reichelstein (1995), 'Specific investment under negotiated transfer pricing: an efficiency result', Accounting Review 70(2), 275-291.

Edlin, Aaron and Stefan Reichelstein (1996), 'Holdups, standard breach remedies, and optimal investment', American Economic Review 86(3), 478-501.

Grossman, Sanford and Oliver Hart (1986), 'The costs and benefits of ownership: a theory of vertical and lateral integration', Journal of Political Economy 94(4), 691-719.

Klein, Benjamin, Robert Crawford and Armen Alchian (1978), 'Vertical integration, appropriable rents and the competitive contracting process', Journal of Law and Economics 21(2), 297-326.

MacLeod, Bentley and James Malcomson (1993), 'Investments, holdup, and the form of market contracts', American Economic Review 83(4), 811-837.

Maskin, Eric and John Moore (1999), 'Implementation and renegotiation', Review of Economic Studies 66(1), 39-56.

McLaren, John (1999), 'Supplier relations and the market context: a theory of handshakes', Journal of International Economics 48, 121-138.

Nishiguchi, Toshihiro (1994), Strategic Industrial Sourcing: The Japanese Advantage, Oxford University Press, Oxford.

Nöldeke, Georg, et Klaus Schmidt (1995), 'Option contracts and renegotiation: a solution to the hold-up problem', RAND Journal of Economics 26(2), 163-179.

Qiu, Larry and Barbara Spencer (2002), 'Keiretsu and relationship-specific investment: implications for market-opening trade policy', Journal of International Economics 58(1), 49-79. 
Schmitz, Patrick (2001), 'The hold-up problem and incomplete contracts: a survey of recent topics in contract theory', Bulletin of Economic Research 53(1), 1-17.

Spencer, Barbara and Larry Qiu (2001), 'Keiretsu and relationship-specific investment: A barrier to trade?', International Economic Review 42(4), 871-901.

\section{A Proof of proposition 1}

It is worth noting that assumption (5) implies that $\Pi_{i l}>0$ for all $i \neq l$.

Consider now the following problem:

$$
\max _{a, j_{b}, j_{s}} \Pi\left(a, j_{b}, j_{s}\right)-\left(\lambda+\frac{1-\lambda}{\mu}\right) a-\left(\lambda+\frac{1-\lambda}{1-\mu}\right) j_{b}-\left(\lambda+\frac{1-\lambda}{\mu}\right) j_{s} .
$$

with $\lambda \in[0,1]$.

The first-order conditions are:

$$
\begin{aligned}
& \Pi_{1}\left(a, j_{b}, j_{s}\right)=\lambda+\frac{1-\lambda}{\mu}, \\
& \Pi_{2}\left(a, j_{b}, j_{s}\right)=\lambda+\frac{1-\lambda}{1-\mu}, \\
& \Pi_{3}\left(a, j_{b}, j_{s}\right)=\lambda+\frac{1-\lambda}{\mu} .
\end{aligned}
$$

The maximization problem (11) has a unique solution, that is, $a(\lambda), j_{b}(\lambda)$ and $j_{s}(\lambda)$.

Note that $a(1)=a^{*}, j_{b}(1)=j_{b}^{*}, j_{s}(1)=j_{s}^{*}$ and $a(0)=\widehat{a}, j_{b}(0)=\widehat{\jmath}_{b}, j_{s}(0)=\widehat{\jmath}_{s}$.

Define

$$
\begin{aligned}
V(\lambda) & =\Pi\left(a(\lambda), j_{b}(\lambda), j_{s}(\lambda)\right)-\left(\lambda+\frac{1-\lambda}{\mu}\right) a(\lambda) \\
& -\left(\lambda+\frac{1-\lambda}{1-\mu}\right) j_{b}(\lambda)-\left(\lambda+\frac{1-\lambda}{\mu}\right) j_{s}(\lambda),
\end{aligned}
$$

and

$$
\begin{aligned}
W(\lambda) & =\Pi\left(a\left(\lambda_{0}\right), j_{b}\left(\lambda_{0}\right), j_{s}\left(\lambda_{0}\right)\right)-\left(\lambda+\frac{1-\lambda}{\mu}\right) a\left(\lambda_{0}\right) \\
& -\left(\lambda+\frac{1-\lambda}{1-\mu}\right) j_{b}\left(\lambda_{0}\right)-\left(\lambda+\frac{1-\lambda}{\mu}\right) j_{s}\left(\lambda_{0}\right)-V(\lambda) .
\end{aligned}
$$

We necessarily have $W(\lambda) \leq 0$ and $W\left(\lambda_{0}\right)=0$. Thus, the function $W(\lambda)$ attains a maximum at $\lambda=\lambda_{0}$. At this point, the first and second order optimality conditions are necessarily satisfied, we thus have $W^{\prime}\left(\lambda_{0}\right)=0$ and $W^{\prime \prime}\left(\lambda_{0}\right)<0$.

The first and second derivatives of $W(\lambda)$ are:

$$
\begin{aligned}
W^{\prime}(\lambda)= & -\left(1-\frac{1}{\mu}\right) a\left(\lambda_{0}\right)-\left(1-\frac{1}{1-\mu}\right) j_{b}\left(\lambda_{0}\right) \\
& -\left(1-\frac{1}{\mu}\right) j_{s}\left(\lambda_{0}\right)-V^{\prime}(\lambda) \\
W^{\prime \prime}(\lambda)= & -V^{\prime \prime}(\lambda) .
\end{aligned}
$$


The first-order condition gives:

$$
\begin{aligned}
W^{\prime}\left(\lambda_{0}\right)= & -\left(1-\frac{1}{\mu}\right) a\left(\lambda_{0}\right)-\left(1-\frac{1}{1-\mu}\right) j_{b}\left(\lambda_{0}\right) \\
& -\left(1-\frac{1}{\mu}\right) j_{s}\left(\lambda_{0}\right)-V^{\prime}\left(\lambda_{0}\right)=0 .
\end{aligned}
$$

The above expression holds for any $\lambda_{0}$. The first derivative of $V(\lambda)$ is then:

$$
V^{\prime}(\lambda)=-\left(1-\frac{1}{\mu}\right) a(\lambda)-\left(1-\frac{1}{1-\mu}\right) j_{b}(\lambda)-\left(1-\frac{1}{\mu}\right) j_{s}(\lambda)
$$

We deduce the expression of the second derivative of $V(\lambda)$ :

$$
V^{\prime \prime}(\lambda)=-\left(1-\frac{1}{\mu}\right) a^{\prime}(\lambda)-\left(1-\frac{1}{1-\mu}\right) j_{b}^{\prime}(\lambda)-\left(1-\frac{1}{\mu}\right) j_{s}^{\prime}(\lambda)
$$

The second order condition $W^{\prime \prime}\left(\lambda_{0}\right)<0$ also holds for any $\lambda_{0}$. We thus have $W^{\prime \prime}(\lambda)<0$ for all $\lambda$. Consequently:

$$
W^{\prime \prime}(\lambda)=-\left(1-\frac{1}{\mu}\right) a^{\prime}(\lambda)-\left(1-\frac{1}{1-\mu}\right) j_{b}^{\prime}(\lambda)-\left(1-\frac{1}{\mu}\right) j_{s}^{\prime}(\lambda)<0 .
$$

Given that $\mu \in] 0,1\left[\right.$, we necessarily have $a^{\prime}(\lambda)>0$ or $j_{b}^{\prime}(\lambda)>0$ or $j_{s}^{\prime}(\lambda)>0$. Suppose for example that $a^{\prime}(\lambda)>0$ and differentiate the FOCs with respect to $\lambda$ to obtain:

$$
\begin{aligned}
a^{\prime}(\lambda) \Pi_{11}+j_{b}^{\prime}(\lambda) \Pi_{12}+j_{s}^{\prime}(\lambda) \Pi_{13} & =1-\frac{1}{\mu}<0, \\
a^{\prime}(\lambda) \Pi_{21}+j_{b}^{\prime}(\lambda) \Pi_{22}+j_{s}^{\prime}(\lambda) \Pi_{23} & =1-\frac{1}{1-\mu}<0, \\
a^{\prime}(\lambda) \Pi_{31}+j_{b}^{\prime}(\lambda) \Pi_{32}+j_{s}^{\prime}(\lambda) \Pi_{33} & =1-\frac{1}{\mu}<0 .
\end{aligned}
$$

The cross derivatives $\Pi_{i j}$ being negative, we get:

$$
\begin{aligned}
& j_{b}^{\prime}(\lambda) \Pi_{22}+j_{s}^{\prime}(\lambda) \Pi_{23}=1-\frac{1}{1-\mu}-a^{\prime}(\lambda) \Pi_{21}<0 \\
& j_{b}^{\prime}(\lambda) \Pi_{32}+j_{s}^{\prime}(\lambda) \Pi_{33}=1-\frac{1}{\mu}-a^{\prime}(\lambda) \Pi_{31}<0 .
\end{aligned}
$$

It immediately follows that:

$$
\begin{aligned}
& \left(\begin{array}{ll}
j_{b}^{\prime}(\lambda) & j_{s}^{\prime}(\lambda)
\end{array}\right)\left(\begin{array}{ll}
\Pi_{22} & \Pi_{23} \\
\Pi_{32} & \Pi_{33}
\end{array}\right)\left(\begin{array}{c}
j_{b}^{\prime}(\lambda) \\
j_{s}^{\prime}(\lambda)
\end{array}\right) \\
= & j_{b}^{\prime}(\lambda)\left(1-\frac{1}{1-\mu}-a_{b}^{\prime}(\lambda) \Pi_{31}\right)+j_{s}^{\prime}(\lambda)\left(1-\frac{1}{\mu}-a_{b}^{\prime}(\lambda) \Pi_{41}\right)<0 .
\end{aligned}
$$

We necessarily have $j_{b}^{\prime}(\lambda)>0$ or $j_{s}^{\prime}(\lambda)>0$. Suppose for example that $j_{b}^{\prime}(\lambda)>0$. The same argument shows that $j_{s}^{\prime}(\lambda)>0$. $\|$ 


\section{B Proof of lemma 1}

Consider any values of $q, a, j_{b}, j_{s}$. Define $g(\mu)=\mu v_{3}\left(q, j_{b}, j_{s}\right)+(1-\mu) c_{4}\left(q, a, j_{b}, j_{s}\right)$.

We get $g^{\prime}(\mu)=v_{3}\left(q, j_{b}, j_{s}\right)-c_{4}\left(q, a, j_{b}, j_{s}\right)>0$.

It follows that $g(\mu)<g(\bar{\mu}) \leq 0, \forall \mu \in[0, \bar{\mu}[$.

\section{Proof of proposition 2}

Let $\left(\widetilde{a}, \widetilde{\jmath}_{b}, \widetilde{\jmath}_{s}\right) \in \Re_{+}^{3}$ be the investment levels of the contracting outcome, solutions of the following first-order conditions:

$$
\begin{array}{r}
(1-\mu) \Pi_{2}\left(\widetilde{a}, \widetilde{\jmath}_{b}, \widetilde{\jmath}_{s}\right)=1-\mu v_{2}\left(\bar{q}, \widetilde{\jmath}_{b}, \widetilde{\jmath}_{s}\right)-(1-\mu) c_{3}\left(\bar{q}, \widetilde{a}, \widetilde{\jmath}_{b}, \widetilde{\jmath}_{s}\right), \\
\mu \Pi_{1}\left(\widetilde{a}, \widetilde{\jmath}_{b}, \widetilde{\jmath}_{s}\right)=1+(1-\mu) c_{2}\left(\bar{q}, \widetilde{a}, \widetilde{\jmath}_{b}, \widetilde{\jmath}_{s}\right), \\
\mu \Pi_{3}\left(\widetilde{a}, \widetilde{\jmath}_{b}, \widetilde{\jmath}_{s}\right)=1+\mu v_{3}\left(\bar{q}, \widetilde{\jmath}_{b}, \widetilde{\jmath}_{s}\right)+(1-\mu) c_{4}\left(\bar{q}, \widetilde{a}, \widetilde{\jmath}_{b}, \widetilde{\jmath}_{s}\right) .
\end{array}
$$

$\left(\widehat{a}, \widehat{\jmath}_{b}, \widehat{\jmath}_{s}\right) \in \Re_{+}^{3}$ are the investment levels of the no-contacting solution:

$$
(1-\mu) \Pi_{2}\left(\widehat{a}, \widehat{\jmath}_{b}, \widehat{\jmath}_{s}\right)=1 ; \quad \mu \Pi_{1}\left(\widehat{a}, \widehat{\jmath}_{b}, \widehat{\jmath}_{s}\right)=1 ; \quad \mu \Pi_{3}\left(\widehat{a}, \widehat{\jmath}_{b}, \widehat{\jmath}_{s}\right)=1 .
$$

Using Lemmas 1 and 2 , it can be easily shown that for all $\mu \in[\underline{\mu}, \bar{\mu}]$

$$
\begin{aligned}
& \Pi_{1}\left(\widetilde{a}, \widetilde{\jmath}_{b}, \widetilde{\jmath}_{s}\right)-\Pi_{1}\left(\widehat{a}, \widehat{\jmath}_{b}, \widehat{\jmath}_{s}\right)=\frac{1-\mu}{\mu} c_{2}\left(\bar{q}, \widetilde{a}, \widetilde{\jmath}_{b}, \widetilde{\jmath}_{s}\right)<0, \\
& \Pi_{2}\left(\widetilde{a}, \widetilde{\jmath}_{b}, \widetilde{\jmath}_{s}\right)-\Pi_{2}\left(\widehat{a}, \widehat{\jmath}_{b}, \widehat{\jmath}_{s}\right)=-\frac{1}{1-\mu}\left[\mu v_{2}\left(\bar{q}, \widetilde{\jmath}_{b}, \widetilde{\jmath}_{s}\right)+(1-\mu) c_{3}\left(\bar{q}, \widetilde{a}, \widetilde{\jmath}_{b}, \widetilde{\jmath}_{s}\right)\right]<0, \\
& \Pi_{3}\left(\widetilde{a}, \widetilde{\jmath}_{b}, \widetilde{\jmath}_{s}\right)-\Pi_{3}\left(\widehat{a}, \widehat{\jmath}_{b}, \widehat{\jmath}_{s}\right)=\frac{1}{\mu}\left[\mu v_{3}\left(\bar{q}, \widetilde{\jmath}_{b}, \widetilde{\jmath}_{s}\right)+(1-\mu) c_{4}\left(\bar{q}, \widetilde{a}, \widetilde{\jmath}_{b}, \widetilde{\jmath}_{s}\right)\right]<0,
\end{aligned}
$$

The rest of the proof is similar to the one of the under-investment result in the no-contracting outcome (see proposition 1). ॥

\section{Proof of proposition 3}

Let $\left(\widetilde{a}, \widetilde{\jmath}_{b}, \widetilde{\jmath}_{s}\right) \in \Re_{+}^{3}$ be the investment levels of the contracting outcome, solutions of the following first-order conditions:

$$
\begin{array}{r}
(1-\mu) \Pi_{2}\left(\widetilde{a}, \widetilde{\jmath}_{b}, \widetilde{\jmath}_{s}\right)=1-\mu v_{2}\left(\bar{q}, \widetilde{\jmath}_{b}, \widetilde{\jmath}_{s}\right)-(1-\mu) c_{3}\left(\bar{q}, \widetilde{a}, \widetilde{\jmath}_{b}, \widetilde{\jmath}_{s}\right), \\
\mu \Pi_{1}\left(\widetilde{a}, \widetilde{\jmath}_{b}, \widetilde{\jmath}_{s}\right)=1+(1-\mu) c_{2}\left(\bar{q}, \widetilde{a}, \widetilde{\jmath}_{b}, \widetilde{\jmath}_{s}\right), \\
\mu \Pi_{3}\left(\widetilde{a}, \widetilde{\jmath}_{b}, \widetilde{\jmath}_{s}\right)=1+\mu v_{3}\left(\bar{q}, \widetilde{\jmath}_{b}, \widetilde{\jmath}_{s}\right)+(1-\mu) c_{4}\left(\bar{q}, \widetilde{a}, \widetilde{\jmath}_{b}, \widetilde{\jmath}_{s}\right) .
\end{array}
$$

The above conditions can be rewritten as follows:

$$
\begin{array}{r}
1-\Pi_{2}\left(\widetilde{a}, \widetilde{\jmath}_{b}, \widetilde{\jmath}_{s}\right)=-\mu \Pi_{2}\left(\widetilde{a}, \widetilde{\jmath}_{b}, \widetilde{\jmath}_{s}\right)+\mu v_{2}\left(\bar{q}, \widetilde{\jmath}_{b}, \widetilde{\jmath}_{s}\right)+(1-\mu) c_{3}\left(\bar{q}, \widetilde{a}, \widetilde{\jmath}_{b}, \widetilde{\jmath}_{s}\right), \\
1-\Pi_{1}\left(\widetilde{a}, \widetilde{\jmath}_{b}, \widetilde{\jmath}_{s}\right)=-(1-\mu) \Pi_{1}\left(\widetilde{a}, \widetilde{\jmath}_{b}, \widetilde{\jmath}_{s}\right)-(1-\mu) c_{2}\left(\bar{q}, \widetilde{a}, \widetilde{\jmath}_{b}, \widetilde{\jmath}_{s}\right), \\
1-\Pi_{3}\left(\widetilde{a}, \widetilde{\jmath}_{b}, \widetilde{\jmath}_{s}\right)=-(1-\mu) \Pi_{3}\left(\widetilde{a}, \widetilde{\jmath}_{b}, \widetilde{\jmath}_{s}\right)-\mu v_{3}\left(\bar{q}, \widetilde{\jmath}_{b}, \widetilde{\jmath}_{s}\right)-(1-\mu) c_{4}\left(\bar{q}, \widetilde{a}, \widetilde{\jmath}_{b}, \widetilde{\jmath}_{s}\right) .
\end{array}
$$

$\left(a^{*}, J_{b}^{*}, J_{s}^{*}\right) \in \Re_{+}^{3}$ are the investment levels of the first-best solution:

$$
\Pi_{2}\left(a^{*}, \jmath_{b}^{*}, \jmath_{s}^{*}\right)=1 ; \quad \Pi_{1}\left(a^{*}, \jmath_{b}^{*}, \jmath_{s}^{*}\right)=1 ; \quad \Pi_{3}\left(a^{*}, \jmath_{b}^{*}, \jmath_{s}^{*}\right)=1 .
$$


Assumption 5 implies $c_{2}$ and $c_{4}$ are decreasing in $q$ and $v_{2}$ is increasing in $q$. It is easily deduced that if $\bar{q}$ satisfies $\bar{q}<q^{*}\left(\widetilde{a}, \widetilde{\jmath}_{b}, \widetilde{\jmath}_{s}\right)$, one has:

$$
\begin{aligned}
\Pi_{1}\left(a^{*}, \jmath_{b}^{*}, \jmath_{s}^{*}\right)-\Pi_{1}\left(\widetilde{a}, \widetilde{\jmath}_{b}, \widetilde{\jmath}_{s}\right) & =(1-\mu)\left[c_{2}\left(q^{*}\left(\widetilde{a}, \widetilde{\jmath}_{b}, \widetilde{\jmath}_{s}\right), \widetilde{a}, \widetilde{\jmath}_{b}, \widetilde{\jmath}_{s}\right)-c_{2}\left(\bar{q}, \widetilde{a}, \widetilde{\jmath}_{b}, \widetilde{\jmath}_{s}\right)\right]<0, \\
\Pi_{2}\left(a^{*}, \jmath_{b}^{*}, \jmath_{s}^{*}\right)-\Pi_{2}\left(\widetilde{a}, \widetilde{\jmath}_{b}, \widetilde{\jmath}_{s}\right) & =\mu\left[v_{2}\left(\bar{q}, \widetilde{\jmath}_{b}, \widetilde{\jmath}_{s}\right)-v_{2}\left(q^{*}\left(\widetilde{a}, \widetilde{\jmath}_{b}, \widetilde{\jmath}_{s}\right), \widetilde{\jmath}_{b}, \widetilde{\jmath}_{s}\right)\right] \\
& +\mu c_{3}\left(q^{*}\left(\widetilde{a}, \widetilde{\jmath}_{b}, \widetilde{\jmath}_{s}\right), \widetilde{\jmath}_{b}, \widetilde{\jmath}_{s}\right)+(1-\mu) c_{3}\left(\bar{q}, \widetilde{a}, \widetilde{\jmath}_{b}, \widetilde{\jmath}_{s}\right)<0 \\
\Pi_{3}\left(a^{*}, \jmath_{b}^{*}, \jmath_{s}^{*}\right)-\Pi_{3}\left(\widetilde{a}, \widetilde{\jmath}_{b}, \widetilde{\jmath}_{s}\right) & =(1-\mu)\left[c_{4}\left(q^{*}\left(\widetilde{a}, \widetilde{\jmath}_{b}, \widetilde{\jmath}_{s}\right), \widetilde{a}, \widetilde{\jmath}_{b}, \widetilde{\jmath}_{s}\right)-c_{4}\left(\bar{q}, \widetilde{a}, \widetilde{\jmath}_{b}, \widetilde{\jmath}_{s}\right)\right] \\
& -(1-\mu) v_{3}\left(q^{*}\left(\widetilde{a}, \widetilde{\jmath}_{b}, \widetilde{\jmath}_{s}\right), \widetilde{\jmath}_{b}, \widetilde{\jmath}_{s}\right)-\mu v_{3}\left(\bar{q}, \widetilde{\jmath}_{b}, \widetilde{\jmath}_{s}\right)<0
\end{aligned}
$$

The rest of the proof is similar to the one of the under-investment result in the no-contracting outcome (see proposition 1). \|

\section{E Proof of corollary 1}

Consider a given value of $\mu$ and suppose there exists $\bar{q}$ such that $\bar{q}=q^{*}\left(\widetilde{a}, \widetilde{j}_{b}, \widetilde{j}_{s}\right)$. The contracting investment levels depend on $\mu$ and $\bar{q}$. Any change in $\mu$ may change the value of $\bar{q}$ compatible with the previous equality.

It is easy to show that the optimality conditions providing the contracting investment level take the following form :

$$
\begin{aligned}
& \mu v_{2}\left(\bar{q}, \widetilde{j}_{b}, \widetilde{j}_{s}\right)+(1-\mu) c_{3}\left(\bar{q}, \widetilde{a}, \widetilde{j}_{b}, \widetilde{j}_{s}\right) \\
& +(1-\mu) v_{2}\left(q^{*}\left(\widetilde{a}, \widetilde{j}_{b}, \widetilde{j}_{s}\right), \widetilde{j}_{b}, \widetilde{j}_{s}\right)-(1-\mu) c_{3}\left(q^{*}\left(\widetilde{a}, \widetilde{j}_{b}, \widetilde{j}_{s}\right), \widetilde{j}_{b}, \widetilde{j}_{s}\right)-1=0 \\
& -(1-\mu) c_{2}\left(\bar{q}, \widetilde{a}, \widetilde{j}_{b}, \widetilde{j}_{s}\right)-\mu c_{2}\left(q^{*}\left(\widetilde{a}, \widetilde{j}_{b}, \widetilde{j}_{s}\right), \widetilde{a}, \widetilde{j}_{b}, \widetilde{j}_{s}\right)-1=0 \\
& -\mu v_{3}\left(\bar{q}, \widetilde{j}_{b}, \widetilde{j}_{s}\right)-(1-\mu) c_{4}\left(\bar{q}, \widetilde{a}, \widetilde{j}_{b}, \widetilde{j}_{s}\right) \\
& +\mu v_{3}\left(q^{*}\left(\widetilde{a}, \widetilde{j}_{b}, \widetilde{j}_{s}\right), \widetilde{j}_{b}, \widetilde{j}_{s}\right)-\mu c_{4}\left(q^{*}\left(\widetilde{a}, \widetilde{j}_{b}, \widetilde{j}_{s}\right), \widetilde{j}_{b}, \widetilde{j}_{s}\right)-1=0
\end{aligned}
$$

Knowing that $\bar{q}=q^{*}\left(\widetilde{a}, \widetilde{j}_{b}, \widetilde{j}_{s}\right)$, the above system can be rewritten as follows :

$$
\begin{aligned}
& v_{2}\left(q^{*}\left(\widetilde{a}, \widetilde{j}_{b}, \widetilde{j}_{s}\right), \widetilde{j}_{b}, \widetilde{j}_{s}\right)-1=0 \\
& -c_{2}\left(q^{*}\left(\widetilde{a}, \widetilde{j}_{b}, \widetilde{j}_{s}\right), \widetilde{a}, \widetilde{j}_{b}, \widetilde{j}_{s}\right)-1=0 \\
& -c_{4}\left(q^{*}\left(\widetilde{a}, \widetilde{j}_{b}, \widetilde{j}_{s}\right), \widetilde{a}, \widetilde{j}_{b}, \widetilde{j}_{s}\right)-1=0
\end{aligned}
$$

The solution of the above system, if it exists, is independent of $\mu$. We conclude that if $\bar{a}$ is chosen so that $\bar{q}=q^{*}\left(\widetilde{a}, \widetilde{j}_{b}, \widetilde{j}_{s}\right)$, the contracting investment level is independent of $\mu$. 
13-7. Search frictions, real wage rigidities and the optimal design of unemployment insurance

Julien Albertini, Xavier Fairise

13-6. Tax me if you can! Optimal non linear income tax between competing governments Etienne Lehmann, Laurent Simula, Alain Trannoy

13-5. Beyond the labour income tax wedge: The unemployment-reducing effect of tax progressivity

Etienne Lehmann, Claudio Lucifora, Simone Moriconi, Bruno Van Der Linden

13-4. Discrimination based on place of residence and access to employment Mathieu Bunel, Emilia Ene Jones, Yannick L’Horty, Pascale Petit

12-3. The determinants of job access channels: evidence from the youth labor market in Franc

Jihan Ghrairi

13-2. Capital mobility, search unemployment and labor market policies: The case of minimum wages

Frédéric Gavrel

13-1. Effort and monetary incentives in Nonprofit et For-Profit Organizations Joseph Lanfranchi, Mathieu Narcy 
12-18. Ageing, changes, and quality of working life

Nathalie Greenan, Mathieu Narcy, Serge Volkoff

12-17. Labor Income Responds Differently to Income-Tax and Payroll-Tax Reforms

Etienne Lehmann, François Marical, Laurence Rioux

12-16. New Evidence of Ethnic and Gender discriminations in the French Labor Market using experimental data: A ranking extension of correspondence testings

Emmanuel Duguet, Loïc Du Parquet, Yannick L'Horty, Pascale Petit

12-15. The Economics of Performance Appraisals

Marc-Arthur Diaye, Nathalie Greenan

12-14. Effect of Age on the Wage Distribution: A quantitative evaluation using US data Sarah Le Duigou.

12-13. Simultaneous causality between health status and employment status within the population aged 30-59 in France

Thomas Barnay, François Legendre

12-12. The Effects of Reduced Social Security Contributions on Employment: an Evaluation of the 2003 French Reform

Matthieu Bunel, Yannick l'Horty

12-11. Has the Quality of Work Improved in the EU-15 between 1995 and 2005?

Nathalie Greenan, Ekaterina Kalugina, Emmanuelle Walkowiak

12-10. Dynamically consistent CEU preferences

André Lapied, Pascal Toquebeuf

12-9. A note on "Re-examining the law of iterated expectations for Choquet decision makers"

André Lapied, Pascal Toquebeuf

12-8. Job Polarization in Aging Economies

Eva Moreno - Galbis, Thepthida Sopraseuth

12-7. Optimal Unemployment Insurance for Older Workers

Jean-Olivier Hairault, François Langot, Sébastien Ménard, Thepthida Sopraseuth

12-6. Entry mode choice and target firm selection: private and collective incentive analysis

Kai Zhao

12-5. Advantageous Semi-Collusion Revisited: A Note

Kai Zhao

12-4. Stricter employment protection and firms' incentives to train: The case of French older workers

Pierre-Jean Messe, Bénédicte Rouland

12-3. Hedonic model of segmentation with horizontal differentiated housing

Masha Maslianskaia-Pautrel

12-2. How to account for changes in the size of Sports Leagues: The Iso Competitive Balance Curves

Jean-Pascal Gayant, Nicolas Le Pape

12-1. What drives Health Care Expenditure in France since 1950? A time-series study with structural breaks and non-linearity approaches

Thomas Barnay, Olivier Damette 
The CNRS Institute for Labor Studies and Public Policies (the TEPP Institute, FR $n^{\circ} 3435$ CNRS) gathers together research centres specializing in economics and sociology:

- l'Equipe de Recherche sur les Marchés, l'Emploi et la Simulation (Research Team on Markets, Employment and Simulation), ERMES, University of Paris II PanthéonAssas

- the Centre d'Etudes des Politiques Economiques de l'université d'Evry (Research Centre focused on the analysis of economic policy and its foundations and implications), EPEE, University of Evry Val d'Essonne

- the Centre Pierre Naville (Research on Work and Urban Policies), CPN, University of Evry Val d'Essonne

- l'Equipe de Recherche sur l'Utilisation des Données Temporelles en Economie (Research Team on Use of Time Data in Economics), ERUDITE, University of ParisEst Créteil and University of Paris-Est Marne-la-Vallée

- the Groupe d'Analyse des Itinéraires et des Niveaux Salariaux (The Group on Analysis of Wage Levels and Trajectories), GAINS, University of the Maine

The TEPP Institute brings together 147 researchers and research professors and $100 \mathrm{PhD}$ students who study changes in work and employment in relation to the choices made by firms and analyse public policies using new evaluation methods. 